\title{
PENANAMAN KONSEP IDENTITAS DIRI BERDASARKAN IMAN KRISTEN MELALUI PERANAN PENDIDIKAN KRISTEN
}

\author{
Neri Astriana Koehuan ${ }^{1}$, Dylmoon Hidayat ${ }^{2}$ dan Chrissya Apitula ${ }^{3}$ \\ ${ }^{1}$ TK Mitra Penabur Gading Serpong, ${ }^{2}$ Universitas Pelita Harapan dan ${ }^{3}$ Apple Tree School \\ 1Email: nerry0601@ gmail.com \\ ${ }^{2}$ Email: dymoon.hidayat@lecturer.uph.edu \\ ${ }^{3}$ Email: icha.apitula14@gmail.com
}

\begin{abstract}
ABSTRAK
Mengenal identitas diri dalam iman Kristen merupakan hal yang krusial bagi kehidupan setiap orang percaya. Pengenalan diri sangat erat kaitannya dengan bagaimana tindakan seseorang menanggapi dirinya, orang lain di sekitarnya, dan juga menunjukkan bagaimana ia megenal Tuhan. Akibat dari tidak mengenal atau salah mengenal diri, dapat membawa dampak buruk bagi diri sendiri, orang lain, lingkungan sekitar, juga iman kepada Tuhan. Dengan demikian, peranan pendidikan Kristen sangat dituntut baik pendidikan Kristen dalam keluarga, gereja maupun sekolah Kristen untuk dapat bekerja sama dengan baik demi tercapainya penanaman konsep identitas diri menurut iman Kristen dalam diri anak-anak. Memang tidaklah mudah untuk mewujudkan penanaman konsep identitas diri sesuai iman Kristen dalam kehidupan anak-anak dalam zaman yang begitu dipengaruhi oleh perkembangan zaman saat ini. Oleh karena itu, perlu adanya kesadaran dari pihak-pihak pelaksana pendidikan Kristen untuk menanamkan prinsip dan nilai-nilai hidup menurut iman Kristen sebagai bekal bagi anak dalam mengarungi kehidupannya menghadapi tantangan perkembangan zaman.
\end{abstract}

Kata Kunci: Identitas diri, iman Kristen, pendidikan Kristen

\begin{abstract}
Knowing identity in the Christian faith is essential to the life of each believer. Understanding the concept of self is closely related to how a person in his daily dealings with him, with others around him and also shows how he represents God. The result of not knowing or knowing yourself wrong can have a bad impact on yourself, others, the environment, as well as faith in God. Thus, the role of Christian education is highly demanded by both Christian education in the family, church and Christian schools to be able to work well together in order to achieve the inculcation of the concept of self-identity according to the Christian faith in children. It is not easy to realize the concept of self-identity in accordance with the Christian faith in the lives of children in an era that is so influenced by the current developments. Therefore, there is a need for awareness from the parties implementing Christian education to instill the principles and values of living according to the Christian faith as a provision for children in navigating their lives to face the challenges of the times.
\end{abstract}

Keyword: Self-Identity, Christian faith, Christian education.

\section{PENDAHULUAN}

Kusumawati, I., \& Zuchdi, D. (2019), dalam Academy of Education Journal, menyatakan bahwa menurut pengamat sosial, terjadi krisis moral karena dari kesalahan lembaga pendidikan nasional yang kurang optimal dalam membentuk kepribadian peserta didik. Lembaga pendidikan dinilai memberikan transmisi yang besar terhadap pengetahuan namun melupakan pengembangan sikap, nilai dan perilaku dalam pembelajarannya. Orientasi pendidikan nasional cenderung melupakan pengembangan dimensi nilai 
(affective domain) merugikan anak atau peserta didik secara individual maupun kolektif. Anak akan mengalami perkembangan intelektual tidak seimbang dengan kematangan kepribadian sehingga melahirkan sosok special yang kurang peduli dengan lingkungan sekitarnya.

Hal serupa juga tak jarang ditemukan dalam dunia pendidikan Kristen. Tidak dapat dipungkiri bahwa banyak remaja-remaja Kristen yang saat ini pola hidupnya dipengaruhi oleh perkembangan dan perubahan yang terjadi di berbagai bidang kehidupan manusia, seperti perubahan sosial, ekonomi, politik, teknologi dan trend yang sedang diramaikan dunia, yang pada akhirnya mengalihkan gaya hidupnya menjadi serupa dengan dunia ini. Hal-hal tersebut berpengaruh terhadap bagaimana seseorang pada akhirnya menilai dan menghargai dirinya dan lingkungan sekitarnya. Nilai dirinya akan diukur berdasarkan pandangan dunia, bukan berdasarkan pandangan Alkitab. Akibatnya para remaja Kristen akan tumbuh dengan: mencari kepuasan diri yang sia-sia, tidak menerima kekurangan diri dengan baik, membandingkan diri dengan orang lain, memandang rendah diri sendiri atau orang lain, dan nilai-nilai negatif lainnya yang kemudian dapat menjadi "pencipta" masalah bagi diri sendiri dan juga bisa membawa dampak buruk bagi sesama dan lingkungan sekitarnya.

Identitas diri dalam iman Kristen bukan berbicara mengenai fisik, pendidikan, karir, etnis, status ekonomi, atau pun prestasi-prestasi yang diraih, dan sebagainya. Mengenal identitas diri yang dimaksud ialah memandang diri sebagaimana Allah memandang. Terkait penanaman konsep identitas diri sesuai iman Kristen, peranan pendidikan Kristen sangat diperlukan, baik pendidikan dalam keluarga, gereja maupun melalui pendidikan di sekolah. Jika pendidikan Kristen hanya berfokus untuk meningkatkan prestasi akademis siswa, dan potensi-potensi diri lainnya tanpa menanamkan persepsi diri yang benar sesuai iman Kristen, maka siswa bisa saja terjebak dalam pengaruh buruk perkembangan teknologi dan tumbuh dalam pengenalan diri yang keliru.

Namun, tidak dapat dipungkiri bahwa untuk dapat mencapai pengenalan diri yang benar di dalam Kristus bukanlah hal yang mudah, banyak tantangan yang harus dihadapi, bahkan dapat dilihat bahwa di era digital saat ini, faktor perkembangan teknologi memiliki pengaruh yang cukup besar terhadap pembentukkan identitas diri anak. Oleh karenanya, pendidikan Kristen perlu memberikan pemahaman Alkitabiah yang baik bagi para peserta didik agar ia mampu membentengi hidupnya dengan kemampuan memilah mana yang baik dan mana yang salah. Dengan demikian maka, penulisan ini bertujuan untuk mengetahui 
peranan pendidikan Kristen dalam menanamkan konsep identitas diri menurut iman Kristen.

\section{METODE PENELITIAN}

Metode yang digunakan pada penulisan ini ialah metode pendekatan kualitatif dengan studi pustaka. Dalam Jurnal Ilmiah Religiosity Entity Humanity, Simon (2019) menyatakan bahwa kajian literatur ialah pengumpulan data melalui berbagai sumber, baik itu sumber buku, jurnal, dokumen, dan sebagainya yang mendukung masalah penelitian (Dupe, 2020).

Sehingga dalam penelitian ini, peneliti akan menggunakan berbagai sumber, seperti: buku-buku tentang Pendidikan dan Iman Kristen atau pun jurnal-jurnal terkait dan sumbersumber lain sebagai pendukung dalam penelitian ini.

\section{HASIL DAN PEMBAHASAN}

\section{Pengertian Umum Identitas Diri}

Dalam Kamus Besar Bahasa Indonesia, identitas diri adalah ciri-ciri atau keadaan khusus seseorang atau biasa disebut juga jati diri. Sedangkan secara psikologi, definisi identitas diri secara umum ialah sebuah kelanjutan menjadi seseorang yang tunggal dan pribadi yang sama, yang dikenali oleh orang lain (Education, 2008, p. 22) Erikson juga memberikan definisi identitas diri yakni identitas diri adalah adanya kesadaran dalam diri individu yang berkembang sejak masa kanak-kanak mengenai apa yang diharapkan di masa depan dan bagaimana individu mempersepsikan diri sendiri serta persepsi orang lain terhadap dirinya (Garey, 2016, p. 109).

Berdasarkan definisi-definisi di atas, maka dapat disimpulkan bahwa secara umum identitas diri berbicara mengenai kesadaran diri yang berorientasi pada ciri khas kepribadian individu, kemampuan beradaptasi, kestabilan emosi, impian masa depan, dan juga persepsi terhadap diri sendiri serta respons terhadap pandangan orang lain tentang dirinya.

Berbeda dengan pandangan dunia secara umum mengenai identitas diri, iman Kristen memandang identitas diri bukan hanya sebatas pandangan secara fisik, potensi, hubungan sosial, pendidikan, karir, dan sebagainya.

\section{Identitas Diri Menurut Iman Kristen}

Calvin menekankan bahwa bila tidak ada pengetahuan tentang Allah, maka mustahil ada pengetahuan tentang diri kita sendiri (Calvin, 2013, p. 7). Untuk memahami dengan 
jelas mengenai konsep identitas diri orang percaya, maka kita perlu melihat kembali kepada kisah penciptaan dan kehidupan setelah penciptaan, serta apa yang dikatakan oleh Sang Pencipta mengenai ciptaan-Nya, yakni tentang manusia.

a. Manusia Diciptakan Menurut Gambar dan Rupa Allah

Penciptaan manusia dikisahkan dalam Kitab Kejadian 1:26 sebagai kisah penciptaan yang unik atau berbeda dengan ciptaan lainnya. Letak keunikkannya ialah ketika Allah hendak menciptakan manusia, Allah terlebih dahulu melakukan perundingan, kemudian memutuskan untuk menjadikan manusia menurut gambar dan rupa Allah, juga diberi akal budi.

Yang, (2018), dalam bukunya Pendidikan Kristen menjelaskan bahwa hal diciptakan serupa dan segambar dengan Allah bukanlah sesuatu hal yang main-main, dan juga bukan merupakan sesuatu yang hal yang sifatnya hanya untuk dibanggakan. Tetapi hal ini untuk menunjukkan betapa berharganya nilai manusia, yaitu makhluk yang diciptakan oleh Tuhan, yang bisa menjadi representasi Allah di atas bumi ini (Calvin, 2013, p. 174).

Dalam bukunya Teologi Sistematika Vol.2, Berkhof menyatakan bahwa berdasarkan pandangan Alkitab esensi manusia tercakup di dalam hal bahwa manusia adalah gambar dan rupa Allah. Dengan demikian manusia sangat berbeda dengan semua makhluk ciptaan yang lain dan menjadi yang tertinggi sebagai mahkota ciptaan Allah atas seluruh ciptaan. Ditegaskan juga bahwa gambar dan rupa Allah ini adalah suatu kualitas yang menjadikan manusia istimewa dalam hubungannya dengan Tuhan (Berkhof, 2011).

Allah menciptakan manusia secara spesial, berbeda dengan ciptaan-ciptaan lainnya. Manusia diberi akal budi, manusia juga diberi kepercayaan oleh Allah untuk berkuasa atas ciptaan lainnya. Dengan melihat pernyataan-pernyataan di atas mengenai esensi manusia yang diciptakan menurut gambar dan rupa Allah, memberikan kesadaran akan betapa istimewa dan berharganya manusia di mata Tuhan. Dan kesadaran ini seharusnya dimiliki oleh setiap manusia agar manusia dapat menghargai dirinya dan menilai dirinya sebagaimana Allah memandangnya. Dengan demikian, manusia dapat memuliakan Allah dengan hidupnya.

Namun, tidak dapat dihindari bahwa kita sekarang hidup dalam citra diri sebagai manusia berdosa. Tidak ada manusia yang terluput dari dosa seperti yang tercatat dalam Roma 3:23: "Karena semua orang telah berbuat dosa dan telah kehilangan kemuliaan Allah". Citra diri manusia yang mulia hilang oleh karena dosa. Dengan demikian dosa menjadi penyebab utama manusia kehilangan pandangan tentang citra dirinya yang 
sesungguhnya, terpengaruh oleh pandangan dunia dan menetapkan cerminan diri menurut ukuran manusia.

b. Kejatuhan Manusia

Alkitab menjelaskan bahwa dosa ialah pelanggaran terhadap hukum Allah. Seperti yang tercatat dalam Kitab 1 Yohanes 3:4, "Setiap orang yang berbuat dosa, melanggar juga hukum Allah", dan juga seperti yang dikatakan oleh rasul Paulus dalam Kitab Roma 8:7: "Sebab keinginan daging adalah perseteruan terhadap Allah, karena ia tidak takluk kepada hukum Allah; hal ini memang tidak mungkin baginya”. Dengan demikian Yohanes mendefinisikan dosa sebagai pelanggaran terhadap hukum Allah, sedangkan Paulus mendefinisikan dosa sebagai perseteruan terhadap Allah oleh karena ketidaktaan terhadap hukum Allah.

Salah satu akibat dari dosa yang begitu berpengaruh bagi kehidupan ialah, manusia kehilangan gambar dan rupa Allah, natur manusia yang diciptakan istimewa menurut gambar dan rupa Allah mulai rusak ketika manusia jatuh ke dalam dosa. Dalam Kejadian 3 dikisahkan bagaimana manusia itu jatuh ke dalam dosa. Adam dan Hawa adalah manusia pertama yang mendapat mandat dari Allah untuk berkuasa atas ciptaan lain dan menjaga serta melestarikan bumi. Namun, Allah juga memberikan aturan atau larangan bagi Adam dan Hawa yaitu mengenai buah pohon pengetahuan tentang yang baik dan yang jahat, yang ada di tengah taman Eden itu tidak boleh dimakan. Disinilah titik mula dosa memasuki kehidupan manusia yaitu Ketika Adam dan Hawa akhirnya memilih untuk melanggar perintah Allah tersebut.

Kejatuhan Adam dan Hawa ke dalam dosa merupakan peristiwa yang berakibat fatal bagi keberlangsungan hidup manusia itu selanjutnya, karena manusia harus menanggung akibat dari dosa tersebut. Baan (2009), menjelaskan akibat-akibat dari dosa, yakni: akibat yang pertama dan terutama yaitu masuknya maut atau kematian. Kehidupan manusia berubah menjadi menderita dan bersusah payah. Hukuman kematian atas dosa memiliki tiga rangkap: Kematian sementara akan menghampiri setiap manusia pada saat jiwa dan raganya terpisah. Kedua, Adam dan Hawa diusir selama-lamanya dari taman Eden. Hal ini menjelaskan keterpisahan manusia dengan Allah, dimana manusia tidak lagi memiliki hubungan yang akrab dengan Allah. Akibat dosa yang ketiga, menyadari ketelanjangan mereka dan merasa sangat malu karenanya. Hal ini menggambarkan kerusakan manusia oleh karena keinginan-keinginannya yang penuh dosa dan tidak dapat dikendalikan, serta hawa nafsunya yang jahat. Selanjutnya yang keempat ialah keadaan manusia yang mati dan 
rusak secara rohani. Hal ini berkenaan dengan murka Allah yang kekal dan membinasakan (Baan, 2012).

Semua manusia mewarisi dosa Adam dan menanggung akibat dari dosa Adam. Inilah yang disebut sebagai dosa warisan. Seperti yang tercatat dalam Kitab Mazmur 51: 7: "Sesungguhnya, dalam kesalahan aku diperanakkan, dalam dosa aku dikandung ibuku". Sehingga tidak ada manusia yang tidak berdosa.

Meskipun manusia jatuh ke dalam dosa sehingga gambar dan rupa Allah yang ada dalam diri manusia telah menjadi rusak, namun Allah tetap mengasihi manusia, Allah tidak membiarkan manusia binasa oleh karena murkanya. Ia melakukan karya penebusan untuk menyelamatkan manusia serta menunjukkkan kasih-Nya kepada manusia.

\section{c. Penebusan (Karya Keselamatan)}

Dosa mengakibatkan manusia kehilangan kemuliaan Allah dan membawa manusia pada kebinasaan dan hukuman dari kekal Allah. Namun, karena kasih Allah yang besar kepada manusia, ciptaan-Nya yang istimewa, yang diciptakan menurut gambar dan rupa Allah, maka Allah berinisiatif untuk menyelamatkan manusia.

Manusia tidak dapat menyelamatkan dirinya sendiri, sehingga ia memerlukan Juruselamat. Agar keselamatan menjadi mungkin bagi para pendosa, maka Anak Allah harus menanggung penderitaan dan kematian di atas kayu salib (Baan, 2012) Kristus mengorbankan diri-Nya di atas kayu salib sebagai korban penghapus dosa bagi umat yang dikasihi-Nya.

Melalui karya penebusan yang telah dikerjakan Kristus bagi setiap orang percaya, kita dapat melihat betapa Allah mengasihi manusia dan betapa berharganya nilai manusia bagi Allah. Artinya manusia memiliki keistimewaan yang luar biasa di mata Allah dibandingkan ciptaan-ciptaan lain. Oleh sebabnya manusia perlu menyadari betapa berharga nilai dirinya bukan dari penampilan, materi, jabatan dan sebagainya yang merupakan pandangan dunia, tetapi melihat dirinya dari sudut pandang Allah. Jika manusia melihat dan menilai dirinya berdasarkan pandangan Allah, ia akan menemukan identitas dirinya yang sesungguhnya dan hal tersebut akan sangat berdampak bagi pandangannya terhadap Allah dan bagaimana ia menyembah Allah.

Mengenal identitas diri sangat penting ditanamkan sejak dari kecil, sehingga anakanak dapat bertumbuh dalam pengenalan diri yang benar serta dapat menilai dan menghargai dirinya dengan cara yang benar. Pengenalan identitas diri yang benar sesuai 
standar Alkitab, akan membawa dampak positif bagi pertumbuhannya dan juga dalam hubungannya dengan sesama dan lingkungan sekitarnya.

Pendidikan merupakan salah satu saran yang dipercayakan Allah untuk membentuk pola hidup manusia. Dengan demikian, maka pendidikan Kristen memiliki tanggungjawab yang besar dalam menanggapi hal ini. Pendidikan Kristen yang dimaksud ialah pendidikan dalam keluarga, gereja dan sekolah Kristen.

\section{Peranan Pendidikan Kristen Dalam Menanamkan Konsep Identitas Diri Menurut Iman Kristen.}

Perkembangan teknologi yang terus melaju pesat membawa begitu banyak manfaat positif bagi kehidupan manusia. Namun, juga dapat berdampak negatif bila salah digunakan, tidak terkecuali bagi kalangan orang dewasa terlebih lagi rentan di kalangan anak-anak dan remaja. Dampak dari pengaruh negatif perkembangan teknologi bisa mengalihkan pemahaman konsep diri yang tidak sesuai dengan ajaran iman Kristen. Oleh karenanya, peran pendidikan Kristen sangat dibutuhkan untuk dapat menanamkan prinsipprinsip hidup menurut iman Kristen agar anak-anak tidak mudah dipengaruhi oleh perubahan dan perkembangan zaman yang terjadi, melainkan dapat mengikuti dan menyesuaikan diri dengan perubahan yang dihadapi dengan cara yang benar, sesuai ajaran iman Kristen.

Mengenai pendidikan Kristen, Wolterstorff mengemukakan bahwa fokus pengajaran yang dilakukan bukan hanya untuk mengembangkan kapasitas rasional dan intelektual saja melainkan juga sebagai pengembangan dari kehidupan kekal, karena tugas utama pendidikan Kristen ialah mendidik untuk kehidupan seutuhnya dari setiap pribadi. Namun, bukan berarti pendidikan Kristen mengabaikan pengembangan rasional dan intelektual. Pengembangan kapasitas diri siswa haruslah mencakup keseluruhan, baik secara spiritual maupun secara akademis (Wolterstorff, 2014, p. 13).

Seperti yang dijelaskan dalam tujuan pendidikan Kristen yakni lebih menekankan pada pemulihan gambar Allah. Wilson, memperjelas tujuan pendidikan Kristen bahwa pada hakikatnya pendidikan Kristen merupakan suatu proses membawa anak pada pemulihan gambar Allah yang telah rusak oleh karena dosa kepada kehidupan yang dewasa secara rohani sehingga anak mampu menjalankan mandat ciptaan-Nya seturut dengan kehendak firman Tuhan (Tety \& Wiraatmadja, 2017, p. 59) Wilhoit juga mengemukakan tujuan pendidikan Kristen sebagai pendidikan yang dilandasi dengan wawasan dunia yang Alkitabiah, yang bertujuan untuk membantu anak-anak menemukan arti Allah dalam hidup 
mereka serta membawa mereka pada pemahaman wawasan dunia Kristen dan menjalani hidup dalam kebenaran Allah (Zendrato et al., 2019, p. 12).

Yang (2018) juga menegaskan bahwa esensi dari pendidikan Kristen adalah membawa orang-orang berdosa keluar dari kegelapan dosa, keluar daari perbudakan daging, keluar dari semua hal yang membawa kepada kematian yang kekal, kepada terang Allah yang Ajaib, kepada kehidupan yang kekal di dalam Tuhan. Ia juga menyatakan bahwa, jika orang-orang Kristen hidup dalam kedewasaan rohani yang baik, maka mereka akan memiliki karakter seperti Kristus (Yang, 2018, p. 31).

Bila anak-anak memiliki pengenalan yang baik akan Tuhan, ia dapat mencapai kedewasaan rohani yang baik pula, sehingga ia mampu menjalani kehidupan Kristen dengan baik pula. Namun, ini bukan hal yang mudah untuk dicapai di tengah-tengah tantangan zaman yang begitu rentan mempengaruhi kehidupan anak-anak saat ini. Perkembangan teknologi, trend-trend masa kini, perubahan sosial dan ekonomi, dan sebagainya yang begitu erat dengan kehidupan.

Orangtua memiliki hak dan kewajiban untuk menentukan pembentukkan kehidupan spiritual anak-anaknya, melalui pendidikan Kristen baik di keluarga, sekolah maupun di gereja. Artinya, orangtua berhak memilih sekolah dan gereja tempat di mana orangtua dapat bekerja sama untuk menanamkan prinsip-prinsip pengajaran iman Kristen dan membentuk kehidupan Kekristenan anak-anaknya. Namun, yang menjadi permasalahan ialah seringkali orangtua melepaskan tanggung jawabnya dan menaruh harapan penuh pada sekolah dan gereja untuk memenuhi kebutuhan spiritual anak, sehingga menimbulkan ketimpangan dalam realisasi pendidikan Kristen bagi anak. Karena, tumpuan utama pendidikan Kristen ialah dari keluarga, kemudian didukung oleh sekolah dan gereja sebagai partner yang saling bekerja sama untuk menanamkan prinsip-prinsip iman Kristen dalam kehidupan anak-anak.

Dengan demikian, diperlukan kerja sama yang baik antara orangtua selaku pendidik utama, sekolah dan juga gereja untuk menanamkan prinsip-prinsip iman Kristen dalam kehidupan anak, agar anak dapat mencapai kedewasaan spiritual. Seperti yang telah dijelaskan sebelumnya bahwa Ketika anak-anak memiliki pengenalan yang baik, maka mereka pun akan memiliki pengenalan yang baik akan konsep diri mereka. Dengan demikian, ia mampu mengarungi kehidupan dengan pedoman iman yang teguh, sehingga anak tidak mudah terbawa arus pandangan dunia yang mengalihkan pandangannya tentang konsep dirinya. 
Selain itu, seperti yang telah dijelaskan sebelumnya, bahwa ketika anak bertumbuh dalam pertumbuhan iman yang benar, memiliki pengenalan yang benar akan Allah, maka ia pun akan memiliki padangan yang benar tentang konsep dirinya. Dengan demikian ia memperoleh bekal yang baik, memampukannya menyikapi setiap problem dalam dirinya, maupun dengan orang lain atau lingkungan di sekitarnya dengan dengan cara benar sesuai prinsip-prinsip iman Kristen yang tertanam dalam dirinya.

\section{SIMPULAN}

Dilihat dari tujuan pendidikan Kristen yakni melandasi pengajaran yang Alkitabiah untuk membawa anak-anak mengenal Allah dengan benar sehingga mereka pun mampu melihat nilai dan identitas diri mereka sesuai tujuan penciptaan Allah, maka jelaslah bahwa pendidikan Kristen memiliki peranan yang sangat penting dalam penanaman konsep diri yang benar menurut ajaran iman Kristen. Namun, oleh karena tugas ini bukanlah hal yang mudah, yang berkembang di tengah pengaruh perubahan zaman yang begitu pesat, maka sudah tentu diperlukan Kerjasama yang baik dari para pihak Pendidikan Kristen, yakni: keluarga, gereja, dan sekolah Kristen untuk dapat mewujudkan tujuan dari pendidikan Kristen ini dan meraih jiwa-jiwa yang tumbuh dalam pemahaman konsep diri yang benar, yang pastinya juga akan berdampak positif bagi invidu, kelompok, maupun lingkungan di sekitarnya.

\section{SARAN}

Zaman akan terus berubah dan akan terus menghadirkan tantangan-tantangan kehidupan yang bisa menjadi ancaman bagi pertumbuhan iman setiap orang percaya. Iman yang lemah dapat mengakibatkan seseorang mudah dipengaruhi. Untuk itulah pendidikan Kristen harus sadar akan tanggung jawabnya terhadap pertumbuhan iman anak-anak, agar anak-anak memiliki keteguhan iman dan tidak mudah terbawa arus pandangan dunia yang berdampak pada pandangan mereka tentang konsep diri, orang lain dan lingkungan sekitar. Agar pelaksanaan pendidikan Kristen dapat terealisasi dengan efektif, maka perlu adanya kerja sama yang baik dari masing-masing pihak pendidik Kristen yang bertanggung jawab yakni pihak keluarga, gereja dan juga sekolah.

\section{DAFTAR PUSTAKA}

Arifianto, YA, \& Santo, JC (2020). Iman Kristen dan Perundungan di Era Disrupsi. ... dan Pendidikan Kristen, e-journal.sttberitahidup.ac.id, https://e- 
journal.sttberitahidup.ac.id/index.php/jan/article/view/73

Awang, JA, Prayitno, ISP, \& ... (2021). Strategi Pendidikan Agama Kristen bagi Remaja dalam Membentuk Konsep Diri guna Menghadapi Krisis Identitas akibat Penggunaan Media Sosial. KHARISMATA: Jurnal ..., e-journal.stajember.ac.id, http://www.e-journal.stajember.ac.id/index.php/kharismata/article/view/64

Baan, G. J. (2012). TULIP (Kedua). Momentum.

Baito, L (2021). Hasrat transhumanisme di tengah pandemi Covid-19: sebuah upaya memahami identitas diri melalui pendekatan teologi interkultural. ... (Jurnal Teologi dan Pendidikan Agama Kristen), sttpb.ac.id, https://www.sttpb.ac.id/ejournal/index.php/kurios/article/view/294

Berkhof, L. (2011). Teologi Sistematika, Doktrin Manusia (sembilan). Momentum.

Calvin, Y. (2013). Institutio: Pengajaran Agama Kristen (Sembilan). Gunung Mulia.

Daniel, AM (2020). Pengaruh religiositas terhadap konsep diri remaja kristen di Tangerang $=$ The effect of religiosity towards self concept of christian adolescent in Tangerang., repository.uph.edu, http://repository.uph.edu/7777/

Dupe, S. I. S. (2020). Konsep Diri Remaja Kristen Dalam Menghadapi Perubahan Zaman. Jurnal Ilmiah Religiosity Entity Humanity (JIREH), 2(1), 53-69. https://doi.org/10.37364/jireh.v2i1.26

Dongoran, D, \& Boiliu, FM (2020). Pergaulan teman sebaya dalam pembentukan konsep diri siswa. Jurnal Educatio FKIP UNMA, ejournal.unma.ac.id, https://www.ejournal.unma.ac.id/index.php/educatio/article/view/560

Garey, E. (2016). Identitas Diri Remaja. Jurnal Youth Ministry, 4(2), 109-119. https://doi.org/10.47901/jym.v4i2.447

Ginting, PS (2020). Penerapan Pendidikan Agama Kristen Untuk Membentuk Jati Diri Remaja Usia 11-15 Tahun di GPdI Panribuan Tahun 2020., repository.uhn.ac.id, http://repository.uhn.ac.id/handle/123456789/5060

Hudaya, M, Maulana, AMR, \& Adzima, F (2020). Konsep Kafir Dalam Tiga Agama Besar (Kristen, Yahudi dan Islam). Kalimah: Jurnal Studi ..., researchgate.net, https://www.researchgate.net/profile/Abdullah-MuslichMaulana/publication/344401017_Konsep_Kafir_Dalam_Tiga_Agama_Besar_Kriste n_Yahudi_dan_Islam/links/5f718015a6fdcc0086434902/Konsep-Kafir-Dalam-TigaAgama-Besar-Kristen-Yahudi-dan-Islam.pdf

Kusumawati, I., \& Zuchdi, D. (2019). PENDIDIKAN MORAL ANAK USIA DINI MELALUI PENDEKATAN KONSTRUKTIVIS. Academy of Education Journal, 10(01), 63-75. https://doi.org/10.47200/aoej.v10i01.272

Karyawati, L (2019). Konsep Pembelajaran Pendidikan Agama Kristen dalam Masyarakat Majemuk. ... Lux Mea (Jurnal Teologi dan Pendidikan Kristen), jurnal.sttkn.ac.id, https://jurnal.sttkn.ac.id/index.php/Veritas/article/view/56

Kawangmani, S, \& Lukmono, IB (2020). ... Pembelajaran Agama Kristen Melalui Mata Kuliah Pendidikan Agama Kristen Di Perguruan Tinggi Terhadap Pemahaman Mahasiswa Kristen Tentang Gambar Diri. Jurnal Gamaliel: Teologi ..., jurnal.sttgamaliel.ac.id, http://jurnal.stt-gamaliel.ac.id/index.php/gamaliel/article/view/48

Lestari, DT, \& Parihala, Y (2020). Merawat Damai Antar Umat Beragama Melalui Memori Kolektif Dan Identitas Kultural Masyarakat Maluku. Hanifiya: Jurnal Studi 
Agama-Agama, journal.uinsgd.ac.id,

http://journal.uinsgd.ac.id/index.php/hanifiya/article/view/8697

Matondang, S (2018). Memahami Identitas Diri dalam Kristus Menurut Efesus 2: 1-10. ILLUMINATE: Jurnal Teologi dan Pendidikan ..., sttbaptis-medan.ac.id, http://sttbaptis-medan.ac.id/e-journal/index.php/illuminate/article/view/2/0

Mawikere, MCS (2021). Konsep Hidup Kekal Menurut Pandangan Dunia Etnis Baliem, Papua Sebagai Potensi dan Krisis Bagi Kontekstualisasi Injil. ... : Jurnal Teologi Injili dan Pembinaan Warga ..., scholar.archive.org, https://scholar.archive.org/work/46cioyxoufeaxml23crzyys2sy/access/wayback/https: //journal.sttsimpson.ac.id/index.php/EJTI/article/download/333/pdf

Ngabalin, M (2019). Berteologi Kontekstual Dari Perspektif Orang Kei Melalui Konsep Duad. VISIO DEI: Jurnal Teologi Kristen, jurnal.sttstarslub.ac.id, http://www.jurnal.sttstarslub.ac.id/index.php/js/article/view/48

Paiman, P., \& Astuti, E. (2012). PENDEKATAN PEMBINAAN MORAL SISWA DI SMP NEGERI 4 KECAMATAN BANGUNTAPAN KABUPATEN BANTULTAHUN PELAJARAN 2010/2011. Academy of Education Journal, 3(2). https://doi.org/10.47200/aoej.v3i2.92

Setiawan, DE (2019). Kelahiran Baru Di Dalam Kristus Sebagai Titik Awal Pendidikan Karakter Unggul. Evangelikal: Jurnal Teologi Injili dan Pembinaan ..., core.ac.uk, https://core.ac.uk/download/pdf/231150598.pdf

Simanjuntak, JM (2018). Belajar Sebagai Identitas Dan Tugas Gereja. Jurnal Jaffray, ojs.sttjaffray.ac.id, http://ojs.sttjaffray.ac.id/index.php/JJV71/article/view/279

Sinaga, TD (2018). PEMULIHAN ALKITABIAH TERHADAP KONSEP DIRI IRASIONAL KAUM MUDA. Missio Ecclesiae, jurnal.i3batu.ac.id, https://jurnal.i3batu.ac.id/index.php/me/article/view/90

Sitorus, H (2020). Teologi Pembuangan: Suatu Kajian Teologis Konsep Teologi Pembuangan Menurut Yeremia. Jurnal Teologi Cultivation, ejournal.iakntarutung.ac.id, http://ejournal.iakntarutung.ac.id/index.php/cultivation/article/view/217

Sukono, D (2019). Teologi “Manusia Baru” Relevankah Di Era Milenial. PASCA: Jurnal Teologi Dan Pendidikan Agama Kristen, journal.stbi.ac.id, https://www.journal.stbi.ac.id/index.php/PSC/article/view/59

Susanto, H (2019). Yesus Sebagai Anak Allah Menurut Injil Matius Dan Implementasinya Dalam Berapologetika. LOGIA: Jurnal Teologi Pentakosta, sttberea.ac.id, http://sttberea.ac.id/e-journal/index.php/logia/article/view/21

Tety, T., \& Wiraatmadja, S. (2017). Prinsip-Prinsip Filsafat Pendidikan Kristen. Evangelikal: Jurnal Teologi Injili Dan Pembinaan Warga Jemaat, 1(1), 55. https://doi.org/10.46445/ejti.v1i1.56

Wolterstorff, N. P. (2014). Mendidik Untuk Kehidupan (ketiga). Momentum.

Yang, F. (2018). Pendidikan Kristen (pertama). Momentum.

Zendrato, J., Putra, J. S., Cendana, W., Susanti, A. E., \& Munthe, A. P. (2019). KURIKULUM BAGI PEMULA - tinjauan teori dan aplikasi dalam perspektif Kristiani (pertama). CV OASE Group. 